\title{
Second-Order Volition and Conflict between Desires
}

\author{
Hengxi $\mathrm{Li}^{1}$, Hengwei $\mathrm{Li}^{2 *}$ \\ ${ }^{1}$ Institute of Philosophy, Chinese Academy of Social Sciences, Beijing, China \\ ${ }^{2}$ Center for the Studies of Language and Cognition, Zhejiang University, Hangzhou, China \\ Email: freeagency@qq.com, "chlhwei@zju.edu.cn \\ Received August $9^{\text {th }}$, 2011; revised September 12 ${ }^{\text {th }}, 2011$; accepted September 22 ${ }^{\text {nd }}, 2011$
}

\begin{abstract}
In Freedom of the Will and the Concept of a Person, Harry Frankfurt put forward a theory that what is essential to be a person is second-order volition. The notion of second-order volition can be used as a key conceptual tool in understanding the conflict between desires. By means of the notion, this paper argues that the conflict between desires in our minds lies in the conflict between second-order volitions, other than the conflict between first-order desires. Based on this claim, this paper suggests that, due to the misunderstanding of the nature of the conflict between desires, the analysis of unwilling addict and wanton addict given by Frankfurt is thus wrong, and in his follow-up articles he made wrong description of the phenomenon concerning the conflict between desires.
\end{abstract}

Keywords: Second-Order Volition; Conflict between Desires; First-Order Desire; Unwilling Addict; Wanton

\section{Introduction}

In Harry Frankfurt's seminal essay Freedom of the Will and the Concept of a Person, he put forward the conception of second-order volition. We think that this conception provides a key conceptual tool by which we shall argue in this paper that the conflict between different desires is not the conflict between first-order desires, but the conflict between second-order volitions about first-order desires. Based on the claim, we shall point out that Frankfurt misunderstood the essence of conflict between desires, which cause him to falsely analyze unwilling addict and wanton addict and describe the phenomena involveing conflict between desires.

\section{Second-Order Volition and the Essence of a Person}

In Freedom of the Will and the Concept of a Person Frankfurt argued that the essence of a person lies in the particular structure of will. As a person, one has not only first-order desires, but also second-order desires. "It seems to be peculiarly characteristic of humans...that they are able to form what I call 'second-order desires' or 'desires of the second order'” (Frankfut, 1988: p. 12). Any desire that concerns about first-order desire can be called second-order desire, which includes two situations: "when he wants simply to have a certain desire or when he wants a certain desire to be his will". What is will? According to Frankfurt, will is "effective desire" (Frankfut, 1988: p. 14). The so-called effective desire is the one that finally bring about an action. It is not hard to see that the simple want of some desire (this kind of second-order desire will be called as second-order desire in the narrow sense for convenience) is different from the want of some desire to be one's will. First of all, second-order desire in the narrow sense indicates that a person has not had the desire he wants, because a person will not have desire to something he has already possessed, and

"Corresponding author. desire always points to a state which is wanted but not satisfied. Secondly, the precondition of wanting some desire to be his will is that he has already had such desire. A person can want some desires he has not had, however he can not want some desire he has not have to be his will. Finally, second-order desire in the narrow sense does not indicate whether or not a person wants the desire he wants to be his will. It is one thing for a person to want a desire and another for him to want the desire to be his will. So to speak, second-order desire in the narrow sense of the word does not have logical connection with second-order volition.

The reason why Frankfurt distinguished two kinds of second-order desire, namely the second-order desire in the narrow sense and the second-order volition, is that he believes that only the second-order volition expresses a connection between desire and will, namely the want of a desire to be his will, and it is through the want of a desire to be his will that a person cares about his own will. Frankfurt thinks the essence of a person is his concern about whether he wants a desire to be his will or which desire he wants to be his will. Since there is no logical connection between the second-order desire in the narrow sense of the word and the second-order volition, it is possible to imagine a creature that has second-order desire but no second-order volition. This kind of creature may want a desire, but it does not care if the desire it wants could be transformed into its will. Whether it works or not, anyway, it goes where the desire takes it to, it does not care it at all. "It is logically possible, however unlikely, that there should be an agent with second-order desires but with no volitions of the second order. Such a creature, in my view, would not be a person. I shall use the term 'wanton' to refer to agents who have first-order desires but who are not persons because, whether or not they have desires of the second order, they have no second-order volitions" (Frankfut, 1988: p. 16). Frankfurt demonstrated his view that the essence of a person lies in second-order volition by comparing the discrepancy between the attitude of a person, here a unwilling addict, and that of a wanton to their respective desire 
(Frankfut, 1988: pp. 16-19). Thus, our intent in this paper is to show that this comparison made by Frankfurt includes wrong description about unwilling addict and wanton addict. Now, let us review how Frankfurt compared them.

Frankfurt describes unwilling addict as follows:

The unwilling addict has conflicting first-order desires: he wants to take the drug, and he also wants to refrain from taking it. In addition to these first-order desires, however, he has a volition of the second order. He is not a neutral with regard to the conflict between his desire to take the drug and his desire to refrain from taking it. It is the latter, and not the former, that he wants to constitute his will (Frankfut, 1988: p. 17).

Although the unwilling addict can not prevent his desire to take drugs from being his will, he concerns about his own will. The fact that he does not want the desire to take drugs to be his will is the right point qualifying an unwilling addict as a person. A wanton addict may in the same way face the conflict between first-order desires. According to Frankfurt, a wanton "does not prefer that one of his conflicting desires should be paramount over the other; he does not prefer that one first-order desire rather than the other should constitute his will” (Frankfut, 1988: p. 18). Anyway, "the wanton addict can not or does not care which of his conflicting first-order desires wins out”. This absence of concern about his own will makes a wanton unqualified to be regarded as a person.

We think that Frankfurt's above description about unwilling addict and wanton is wrong since neither unwilling addict nor wanton has conflict between first-order desires; furthermore, I will argue that neither unwilling addict nor wanton has conflict between desires at all. Frankfurt's misunderstanding about the essence of conflict between desires made him falsely thought that both the unwilling addict and the wanton addict have or possibly have conflict between first-order desires.

\section{Conflict between Desires}

Perhaps we can distinguish two kinds of desire: desire of state and desire of action. When we want to do something, we always want to fulfill a desire of state by taking the action. In other word, desire of action is always motivated by desire of state. However, not every desire of state can motivate our desire of action. The essence of desire of an action is to fulfill the desire of state that trigger our desire of this action. Since the essence of desire of action is to achieve other desires, thus, 1) when a person truly believes that his desire can not be achieved through action, this desire will not trigger a desire of an action. A lot of people have a desire of flying in the sky, however they will definitely mock the first one who wants to achieve this desire since they do not actually believe human being can fly into the sky, and here as a desire of being in certain state, the desire of flying in the sky fails to trigger the desire of action. Certainly the person who has the desire of action probably does not have a belief about whether his action can fulfill his desire, however it is not the case at all that he does not believe his action may achieve his desire. Sometimes our holding the mentality of trying to do something is the case; 2) Even if a person believes he can fulfill a desire, the desire itself may not sufficiently trigger a desire of action. Obviously, a person always has a lot of desires that he believes to be achievable, but he may not have the capacity to fulfill them simultaneously. There are different factors that result in the lack of the capacity. For example, sometimes we do not have such capacity logically. A person who plans to give up smoking can not have capacity that makes him fulfill the desire to smoke, while fulfilling the desire to refrain from smoking at the same time. Likewise, a person's material power may fulfill each of different desires, however, his material power is not enough to fulfill all such different desires at the same time. Anyway, we can not fulfill all our desires by only action.

Since an action can only fulfill a specific desire, and as a person, one have second-order volition, the problem of deciding which desire to be fulfilled matters to us. Sometimes, to solve this problem is not too much intractable, since according to the strength of the desire, or its importance to us, we can easily decide which desire to be fulfilled. Obviously, however, the strength and the importance of different desires seem to put the same influence on us, which makes us in a quandary and do not know how to make a decision. We constantly look for reasons for the fulfillment of each desire, just like the balance that swings restlessly due to the constant weight change on two trays. When this happens, we are facing conflict between desires, more specifically, the conflict of second-order volition, because when we face conflicts, what constitutes a conflict lies in that we want not only this desire of actions to be our will, but also another one, however, in view of foregoing reasons, only one desire of actions can become our will. Conflict between desires exists only when different desires of actions compete to become the next action. Desires of actions are maybe various, but one action procedure can only represent one desire of action, and when different desires of action are required to occupy the next action procedure, a conflict or competition emerges. Hence we can see that the essence of conflict between desires lies in the conflict that occurs when one decide which desire of action he want to put into action, and which desire of action he want to be his will, in other words, conflict between desires is actually the conflict of second-order volitions.

The fact that the conflict between second-order volitions is essential to conflict between desires indicates that different desires themselves related to conflicting second-order volitions do not conflict with each other. Second-order volition, namely wanting a desire to be will, expresses a relation between the person and his desires which have occurred in him, while conflict between desires is essentially the relation between different second-order volitions. We can say that conflict between desires is the conflict between second-order volitions that a person triggers in his internal world: since only one desire can become his next will, the two second-order volitions that result from not only wanting this desires of action to become his next will but also that thus constitute a conflict. Our deliberation, balance and weigh again and again, and thinking over is not a process to simply choose a desire from all desires, but a process to choose one from different second-order volitions to solve the conflict caused by the person oneself. In fact, it is just a process of making decision.

The process of making a decision starts with the threshold that we establish for whether we endorse a desire of action to be our will, and we ourselves are the guardians of this threshold. Each desire of action passing through this threshold is what we want to be our will. Even for those desires that we take actions immediately once they appear without any deliberation, the reason that they become our wills is that we actually accept the second-order volition of the desires. No matter how negligible a desire is, it will not become a person's will by itself. When we say that a desire cause an action, the view that implies in such 
statement is that it is we ourselves that accept or identify this desire to become our will and cause an action, namely, a second-order volition. When we face conflict between desires this point will become more obvious because the essence of conflict between desires just is the conflict between second-order volitions, and in this situation we have to decide to endorse which second-order volition.

\section{Unwilling Addict}

According to Frankfurt's description about unwilling addict quoted above, unwilling addict faces a conflict between firstorder desires: he wants to take the drug, and he wants to refrain from taking it. This part of the paper will present an analysis on unwilling addict, and demonstrate that unwilling addict does not have a conflict between first-order desires.

Conflict between desires can be divided into two types: the conflict of fulfilling which desire of action, and the conflict of whether to fulfill a desire of actions or not. The general form of the first type can be described as: the conflict between wanting desire of action A to be will and wanting desire of action B to be will. Certainly, desires involved in this type of conflict can be more than two. Nevertheless, no matter how many desires are involved in, the essence of conflict between desires remains the same. Furthermore, it is through this type of conflict that we see that the essence of conflict between desires rightly rests in the conflict of second-order volitions. No matter what desires of action they are, the desire of action $A$ and $B$ itself will not conflict with each other. A person may desire to purchase both a house and a car, but he can only afford one of them. In such situation, his two desires alone may not constitute a conflict because it is possible that based on his current situation, he wants the desire to buy a house to be his will, and do not want another desire to buy a car to be his will at all. Yet, this does not mean that he does not desire a car, but that based on current situation, he does not want to transform the desire to buy a car into his will. The desire to buy a car may appear in his mind unexpectedly, however, whether to transform this desire to his will depends on the person himself. It is because the second-order volition completely depends on the person himself that we can say that conflict between desires is engendered by the person himself. Thus, only when he wants to use the money to buy both a house and a car will these two desires conflict, because this situation means he want the desire to buy a house to be his will, and also want another desire to buy a car to be his will, but he can only identify one of these two second-order volitions, in other words, he can only endorse one desire of action, desire to buy a house or buy a car, as his will.

\footnotetext{
${ }^{1}$ Here we need to make some distinctions among the following concepts or relationship between concepts, such as not to want to take action A, to want not to take action A, to want to take action A and not to want to take action $\mathrm{A}$, and to want to take action A and to want not to take action A. When a person wants to take action $A$, he is not able not to want to take action $A$ at the same time; Not to want to take action A is not a desire, but a logical negation of a desire. But when a person wants to take action $\mathrm{A}$, he can certainly want not to take action A, to want not to take action A is an expression of a desire, just as to want to take action A is. Consider the difference between not to want to take cigarette and to want not to take cigarette, a person is not able both to want to take cigarette and not to want to take cigarette, however a person who wants to take cigarette certainly is able to want not to take cigarette. Not to desire to do something is certainly different from to desires not to do it, to want to take action A contradicts logically with not to want to take action A, and to want to take action A is mentally in conflict with to want not to take action A.
}

Another type of conflict between desires is the conflict of whether to fulfill a desire. Actually, we have mentioned this type of conflict in part II, namely, we do not possibly have capacity to fulfill two different desires logically, although we can fulfill each of them separately. We can describe the general form of this type of conflict as: a conflict between wanting the desire to take action A to be will and wanting the desire not to take Action A to be will. ${ }^{1}$ When Frankfurt says that the unwelling addict faces conflict between desires, what Frankfurt means is that the unwilling addict faces conflict of whether to fulfill the desire to take the drug or not. Frankfurt suggests that unwilling addicts face a conflict between first-order desires, which is conflict between two desires of action. Obviously, Frankfurt thinks that the two first-order desires in conflict are the desire to take the drug and the desire to refrain from taking it.

The desire to take the drug and the desire to refrain from taking it are two desires in conflict. And if the desires are both desires to act-first-order desires, then it indicates that the essence of conflict between desires is not the conflict of secondorder volitions because the desire to act is the first-order desire, but not the second-order volition which is a desire about a desire, expressing a relationship between a person and desires to act occurring in him. Hence if we insist that conflict between desires is conflict of second-order volitions, we have to analyze these two desires to take the drug and refrain from taking it, figuring out if there is anything that bewilder us and make us to believe this conflict is conflict between desires to act, or the conflict between first-order desires described by Frankfurt.

It is definitely felt that the relationship between the desire to take the drug and the desire to refrain from taking it is different from the relationship between the conflict of the desire to buy a house and the desire to buy a car. In the latter relationship, to buy a house and to buy a car are logically unrelated, any of which does not entail the other. However, the desire to take the drug and the desire to refrain from taking it is another situation. Obviously, desire to take the drug is a pure first-order desire. The desire to take the drug, under specific physical condition, will inevitably happen to the addict. Unlike the desire to take the drug. The desire not to take the drug or to refrain from taking it, however, is inseparable from and depends on the desire to take the drug, in fact, the former entails the latter: only if a person desires to take the drug, he may desire not to take the drug.

The particularity of the desire not to take the drug goes beyond its entailment of the desire to take the drug. The firstorder desire to take the drug does not depend on the person himself, but just as whether a person want the desire to buy a car to be his will totally depends on a person himself, the desire not to take the drug totally depends on the person himself. Actually, the fact that the desire to refrain from taking the drug depends on a person himself demonstrates such desire is a brief description of a second-order volition. A person desires not to take the drug, or, put it more specifically, he restrain himself from fulfilling the desire to take the drug, is actually that he does want the desire to take the drug not to be his will. Thus, to desire not to take the drug does not simply entail the first-order desire to take the drug, furthermore, it is the difference in the level of desire that leads to the entailment. The former is a second-order volition concerned about the latter, and the latter is just a first-order desire. The desire not to take the drug is actually a negative second-order volition of the desire to take the 
drug, a first-order desire, hence it must entail the desire to take the drug.

Thus, when we say that the desire to take the drug and the desire not to take the drug, or the desire to refrain from taking he drug, are two conflicting desires, the desire not to take the drug is actually negative second-order volition of the former. Now here arises the question: when the desire not to take the drug causes conflict between desires, is the desire to take the drug just expresses a first-order desire about action? To put it in another way, is conflict between desires faced by the addict a conflict between the addict's first-order desire to take the drug and his negative second-order volition? Frankfurt gives an affirmative answer to this question in Three Concepts of Free Action. He says "there is a conflict within him, between a first-order desire to do what he actually does and a secondorder volition that this first-order desire not to be effective in determining his action” (Frankfurt, 1988: p. 48). First of all, I think Frankfurt denies his description about unwilling addict in Freedom of the Will and the Concept of a Person, since herein what the addict faces is no longer the conflict between firstorder desires, but the conflict between first-order desire and second-order volition. Secondly, Frankfurt does not carry this denial throughout, and he misunderstands the basic relationship between a person and his desire, namely, the one of secondorder volition put forward by him. As we have stated clearly, first-order desire will not drive a person directly to act. Even an desire that we in no way hesitate to fulfill implies second-order volition, namely, we want this desire to be our will, instead of wanting this desire not to be our will. And this is the key point when Frankfurt reveals that the second-order volition is the essence of a person: We not only have first-order desire, but as a person, we have to answer the question of whether we endorse the first-order desire to be our will. Hence when the desire to take the drug conflicts with the desire to refrain from taking it, the negative second-order volition of the former, the desire to take the drug is not simply a first-order desire as an internal primitive drive, but actually affirmative second-order volition of this desire to act: to make the desire to take the drug to be one's own will.

It is imaginable of the mental activities experienced by a drug addict in conflict between desires: he is ceaselessly looking for reasons for his two desires in conflict with each other, which is like a person who is incessantly adjusting weights onto the two trays of an unbalanced scale. A person is not to look for reason for anything beyond his control. So-called somethingbeyond-one's-control means something about which one can make no difference that he wants by one's own efforts. The first-order desire to take drugs occurs with a particular strength in one's mind, which is totally beyond his limitation of control, and the first-order desire inevitably and persistently drives him to take an action to meet it, which is also beyond his control. Therefore, when he is to look for reasons for the desire to take drugs, he does not do this for the first-order desire. Although the addict is incapable of controlling the power inherent in the first-order desire, he at least believes that he can make the desire to take drugs or the desire to refrain from taking drugs be his will, and that he can express the second-order volition on the desire to take drugs. So the process to look for reasons is in fact a process to eventually endorse a second-order volition. When the addict is to look for reasons for his own two desires in conflict with each other, he literally intend to establish his own attitude toward the desire to take drugs in the end: he have to make the scale of attitude stop, and he have to make a decision of whether to take drugs or not, in order to stop swaying between his two second-order volitions. So what the addict is really doing is to look for reasons for the two second-order volitions on the desire to take drugs. To put it in another way, when the addict facing a conflict between desires, his mental activity of looking for reasons indicates that what he is facing is a conflict of second-order volitions.

Based on above argument, we can say that Frankfurt's view that an unwilling addict faces first-order conflict is wrong, for he does not face a conflict between first-order desires. When we say the unwilling addict faces the conflict between to want to take the drug and to refrain from taking it, he actually faces a conflict between two second-order volitions, a conflict between affirmative second-order volition of the desire to take the drug and its negative second-order volition.

\section{Wanton Addict}

In the elucidation of view that the essence of a person lies in his possession of second-order volition, Frankfurt imagined a logically possible creature, namely a wanton addict, as a contrast to the unwilling addict. Frankfurt thinks a wanton addict also may encounter a conflict between first-order desires just as an unwilling addict does (Frankfurt, 1988: p. 18). However, unlike an unwilling addict, a wanton addict does not care about his will. For him, there is no problem of which desire he want to be his will. It is this difference that distinguishes a wanton addict from an unwilling addict.

In fact, the concept of the wanton addict proposed by Frankfurt for the sake of explaining his theory is rather ambiguous. On the one hand, a wanton addict may experience the conflict between first-order desires; on the other hand, the wanton addict may not care about his will when he experiences such conflict. First of all, my above argument that conflict between desires that an unwilling addict faces is the conflict of second-order volitions is true of the case of a wanton addict. That is to say: the conflict between first-order desires does not possibly exist in the wanton addict because conflict between desires does not possibly exist on the first-order level. Secondly, what does it mean by claiming that the wanton addict who faces the conflict between first-order desires does not care about his will? Obviously, the wanton does not possibly have the conflict of second-order volition as we understand, since in our definition wanton is the creature who owns first-order desire but no second-order volition. Furthermore, if a person is facing conflict of second-order volition, it is impossible for him to be careless of his own will because the conflict of second-order volition is caused by one's concern about his own will. The statement that an agent faces the conflict of second-order volition but does not care about his own will is paradoxical. So the thesis that a wanton addict faces the conflict between first-order desires and does not care about his will is the most confused. How is it possible for him not to concern about his will when facing conflict between desires? It goes beyond our understanding unless Frankfurt explicated what the conflict between first-order desires really mean. Only when understanding what the conflict between first-order desires refers to can we comprehend why the concept of a wanton who faces the conflict contains no contradiction in itself.

Then what can a wanton facing the conflict between firstorder desires refer to? It might refer to a situation in which there is not a conflict between desires at all, but which is possi- 
bly misunderstood as a conflict. Frankfurt says: "in any event he is, in respect of his wanton lack of concern, no different from an animal” (Frankfurt, 1988: p. 18). Frankfurt thinks that there are two causes responsible for a wanton's carelessness of his own will, "it is due either to his lack of the capacity for reflection or his mindless indifference to the enterprise of evaluating his own desires and motives" (Frankfurt, 1988: pp. 18-19). Obviously, the latter cause is essentially different from the former one, since evaluation must contain reflection. The latter will not be analyzed here since, as stated before, it is difficult to understand how a wanton in the conflict of first-order desire does not care about his will, while a wanton, if he cares about his will, could not be mindless indifferent to the evaluation of one's desire or motivation.

It is the lack of the capacity for reflection that causes a wanton who faces the conflict between first-order desires to be careless of his will. However, a further claim can be made that when the capacity for reflection is absent, there would not be a conflict between desires at all, a conflict between first-order desires, if it is understandable. Conflict between desires requires that a creature facing a conflict between desires must be capable of reflecting. When a desire arises in the creature, no matter whether we respond to it immediately or not, its capability for reflection enables it to take the desire as an object of its reflection. It is the capacity that opens up an inner mental space for it, the emergence of which cuts off the direct connection between desires and bodily motions, temporarily suspends and sets aside the internal driving force of desire, and makes the desire an evaluated and examined object by reflection; the purpose of these reflective mental activities is to answer whether to allow this driving force to function or not and to make a final decision. It is in this inner mental space that we can analyze different desires, compare them, evaluate them and express our attitudes toward them. As an attitude to a first-order desire, second-order volition arises just in this inner mental space. A desire passing through the inner mental space is, of course, possibly allowed to engender a bodily motion, but it is essentially different from a desire which directly and immediately triggers a bodily. The fundamental difference originates from the fact that the desire passing through the mental space of reflection has already been a second-order volition.

There could not be conflict between desires without the capacity for reflection because only such capacity can create an inner mental space which can accommodate different desires and is an arena in which different desires compete. However, lack of reflection does not mean there is no force to prevent a desire from fulfillment. When we say that desire directly causes bodily action, what we mean is not that as long as a desire appears, it must trigger corresponding bodily action, but that the direct connection between desire and bodily action will not be cut off by an inner mental space. If we treat animals as a creature without reflection, we might as well imagine what the connection between desire and bodily action is like to be. As far as an animal without reflection is concerned, once a desire ${ }^{2}$ arises in it, it will either immediately cause corresponding bodily action or not cause such action. In the latter case, however, no bodily action may be due to an opposite mental force to occur in him. For example, when a cat desires to eat the fish on

\footnotetext{
${ }^{2}$ When it comes to animal desire, what we talk about is the desire simply as inner drive. Animals certainly can not express such desire by language, they can not say: "I want...". However, as far as inner drive is concerned, it is just the same force that drives an addict to take the drug, when he says: "I want to take drugs".
}

the table but fears punishment, the desire to eat the fish does not prompt a corresponding bodily action due to the fear of punishment. For a cat, if we are sure that it has no capacity of reflection, it can not form an inner mental space in which it can compare different mental forces, including desires, thus these forces is simply opposite, and can not constitute a conflict.

So a wanton addict without the capacity of reflection has no conflict between desires, no matter first-order desires or second-order desires. Rather, conflict between desires is simply he conflict of second-order volitions. The lack of capacity for reflection already thoroughly shut the door for the emergence of conflicts of desires. What they actually experience is merely the continuous occurrence of opposite driving forces in succession of time, which on no account can be regarded as conflicts of desires although we might misunderstand that they constitute the conflict.

\section{Conflict between Desires and Struggle of Desires}

As argued above, conflict between desires can not arise on first-order level, and conflict between desires is meant to be conflict of second-order volitions about first-order desires, thus 1) neither unwilling addict nor wanton addict have conflict of first-order desire, 2) according to definition, if wanton addict does not have second-order desire, they does not have conflict between desires either. However, unwilling addict needs further investigation and here arises the question: does unwilling addict have conflict between desires? This question matters because its answer will show to us what conditions are necessary for the existence of conflicts between desires.

According to the explanation of conflict between desires proposed by this paper, when a person experience conflict between desires, he is in a situation in which he want not only this desire to be his will but also that desire to be his will at the same time. As mentioned earlier, the process of conflict between desires is the process of making decision. The reason why we sway between different desires is that we do not know how on earth to decide. According to Frankfurt, under this situation, a person "does not know what he really wants" (Frankfurt, 1992: p. 9). If conflict between desires means a person doesn't know how to make a decision, then conflicts of desires will disappear immediately once he makes the decision. For an unwilling addict, although the irresistible desire of taking the drug makes him unable to make a decision on whether to take the drug or not since we can only make decision on things under our control. Although we can not say that an unwilling addict can make a decision, but it's safe to claim that, according to Frankfurt, an unwilling addict has wholeheartedly endorsed the second-order volition of wanting the desire to refrain from taking the drug not to be his will. And this wholehearted endorsement equivalent of making a decision eliminates conflict between desires.

According to the theory on conflict between desires put forward in this essay, for unwilling addict, and for anyone who makes decision after experiencing conflict between desires, once they make decision, conflict between desires will disappear immediately. Nevertheless the conclusion is different from the viewpoint about conflict between desires held by Frankfurt. In many places, Frankfurt made descriptions of a person's desire situation when he makes decision, herein we chose two examples:

When someone identifies himself with one other than with another of his own desires, the result is not necessarily to 
eliminate the conflict between those desires, or even to reduce its severity, but to alter its nature. Suppose that a person with two conflicting desires identifies with on rather than with the other. This might cause the other-the desire with which the person does not identify - to become substantially weaker than it was, or to disappear altogether. But it need not. Quite possibly, the conflict between the two desires will remain as virulent as before. What the person's commitment to the one eliminates is not the conflict between it and the other. It eliminates the conflict within the person as to which of these desires he prefers to be his motive. The conflict between the desires is in this way transformed into a conflict between one of them and the person who has identified himself with its rival. That person is no longer uncertain which side he is on, in the conflict between the two desires, and the persistence of this conflict need not subvert or diminish the wholeheartedness of his commitment to the desire with which he identifies (Frankfurt, 1988: p. 172, original emphasis).

As in the case of the unwilling addict, the unity of a healthy will is quite compatible with certain kinds of virulent psychic conflict. Wholeheartedness does not require that a person be altogether untroubled by inner opposition to his will. It just requires that he must be resolutely on the side of the forces struggling within him and not on the side of any other. Concerning the opposition of these forces, he has to know where he himself stands. In other words, he must know what he wants (Frankfurt, 1992: p. 9).

If our understanding is right, it is very obvious, according to Frankfurt, that conflict between desires still exists when someone has made decision. In fact, the fundamental reason why Frankfurt makes such description of the desire situation in decision making is that he thinks there exists conflict of first-order desires. However in the first paragraph quotation, it is also found that Frankfurt appears to think there exists conflict of second-order volitions, "It eliminates the conflict within the person as to which of these desires he prefers to be his motive". Frankfurt thinks decision eliminates conflict of second-order volition and makes the original conflict of first-order desire be transformed into conflict between a first-order desire and a person who has second-order volition. As a result, there are three conflicts according to Frankfurt. Yet we hold that there are no three conflicts, but only conflict between desires as conflict of second-order volition, and once a decision is made, conflict between desires does not change its nature, but disappear. There is no anything like changed nature of conflict between desires, what does change is the nature of first-order desire itself. Then if decision making eliminates conflict of second-order volitions, what is the conflict that Frankfurt mentioned not be eliminated? First of all, we have demonstrated that there is no conflict of first-order desire. Secondly, when we make decision, conflict between desires disappears although the first-order desires that constitute conflict may not disappear. A person who is on a diet has made up his mind not to eat any fat, though he probably swallows saliva when he sees a roast duck and his desire to eat it as a pure first-order desire still drive him. Here, the key point is that the desire to eat a roast duck has not constituted a second-order volition any more. With the decision being made, his desire to eat the duck has returned into a pure first-order desire immediately as an internal driving force. Therefore when a decision is made, the conflict of the desires disappears, which results in the change of nature of the desire that we do not identify: it no longer constitute a second-order volition and returns into a first-order desire as pure driving force.

When a person makes decision, this pure first-order desire as driving force, unlike Frankfurt says, collides with the one who makes decision. Actually, we can hardly understand what this kind conflict is unless it means that, even after the decision is made, this first-order desire purely functioning as driving force still intrudes into us. To distinguish conflict between desires from struggle of desires may help us to understand that such intrusion is not a kind of conflict. Imagine that the person who is on a diet has decided not to eat roast duck, however the roast duck still stimulates his sense and even the imagination of the duck drives him to eat it. Since he has decided not to take roast duck, he will not have second-order volition of desire to eat duck because the existence of this second-order volition means he has not made the decision. He is certainly still struck by desire even after he has made the decision, however, what is essential is that he no longer thinks over the desire, and no longer thinks over how to act. Once determined, the person who is on a diet no longer deliberate on whether to make desire to eat duck to be his will. Instead, what he needs to do is to struggle with the attack from the desire in order to prevent the desire to eat duck from constituting a second-order volition again. A person will not conflict with his first-order desire; however, he will struggle with his first-order desire. When a person is struggling with his desire, he does not think over the desire, but make an action targeting at the desire. Struggle happens after the decision is made while conflict happens before that. A person probably makes a decision, or even makes up his mind, however, when he struggles with first-order desire, he may become irresolute and begin to change his mind. The experience of irresolution which we are rather familiar with means that a person returns from struggling with the desire to facing conflict between desires, indicating that the desire which becomes the object of our struggle after decision is made acquires its second-order volition in our inner mental space. The transforming process from hesitation to resolution and to the change of mind as we always experienced, so to speak, is in fact the very process in which the conflict between desires is transformed to be the struggle against desire and then return back to conflict between desires again.

Thus, when an addict is called an unwilling addict, it does mean that there is no conflict between desires in him at all, but not that the addict will not struggle with his irresistible desire.

Although we have made the conclusion that unwilling addicts do not have conflict between desires, the situation of unwilling addict is prescribed, especially his irresistible desire for drugs. However, regarding those inner subjective experience such as desire and conflict between desires, a significant question remains to be answered: whether or not does the drugger himself believe that his desire is irresistible? By raising this question here, it's meant to articulate that the occurrence of conflict between desires is related to one's belief towards his desire.

Suppose that a drugger desire to take the drug and he must have a belief towards this desire. Firstly, suppose that this belief is: he believes this desire is irresistible to him. ${ }^{3}$ Although

\footnotetext{
${ }^{3}$ Here we do not care about whether desire of this drugger is actually irresistible or not, what we care about is his belief about whether he can resist it. Actually whether it is irresistible or not has no connection with whether he believes in the irresistibility of this desire. It is probably that desire of taking he drug can be resisted, but he does not believe that it can be resisted, and vise versa. My purpose herein is to demonstrate that conflict between desires has connection with a person's belief about whether a desire is controllable.
} 
the desire seems irresistible to him, he still can express his attitude towards this desire, which is a second-order volition. But no matter what attitude he expresses, once he believes this desire to take the drug is irresistible, conflict between desires will not happen. The existence of conflict between desires indicates that a person does not know how to decide his will, but he believes his final will depends on his choice from conflicting second-order volitions. As long as desire to take the drug is irresistible, it means his will has been decided by irresistibility of desire. Actually, this is the very meaning of "being irresistible". Since it is believed that a desire is irresistible, then it is meaningless to think over whether to fulfill this desire. Thus, when an drugger believes his desire to take the drug is irresistible, conflict between desires will not arise. At this point, the belief that a desire is irresistible functions as a sufficient condition for the absence of conflict between desires.

If the drugger's belief towards the desire to take the drug is it's resistible, then how it will be? It will be uncertain. He may completely accept this desire to be his will, at this point he is a willing drugger. However, he may also resist this desire from the beginning and struggle against his desire of taking the drug, certainly he may face conflict between desires, and decide whether to make desire to take the drug to be his will or not. Thus to believe a desire is resistible may not lead to conflict between desires. At this point, the belief that the desire can be resisted is a necessary condition for conflict between desires to arise because conflict between desires arise only when we believe the desires we are facing are controllable. Through the investigation into drugger's belief towards desires, the conclusion is that whether conflict between desires exists or not has no connection with actual controllability of desire, but related to a person's belief about whether his desire is controllable or not. Although a person's belief about whether his desire is controllable or not may be wrong, this belief is vital for whether a person will actually face conflict between desires.

\section{Conclusion}

The major point that we have argued for in this paper is that: conflict between desires is conflict of second-order volitions and can not arise on the first-order. Based on the claim, we point out the mistake in Frankfurt's viewpoint regarding conflict between desires, especially his mistake in treating conflict between desires as conflict of first-order desire. Probably this mistake can be taken as another example illustrating how language gives rise to confusions in our thoughts. Imagine how we report to others about our experience of conflict between desires. We will say "I want to do this, and I want to do that as well". The way of our reports that seems to be concerned only with two first-order desires to act easily misguides us to the wrong impression that it's just a conflict of two first-order desires. When Frankfurt proposes the essence of a person lies in second-order volition, he opens up a gate toward the understanding of human agency; yet he missed the first stream of light coming through this gate when he mistook conflicts of desire as conflict between first-order desires.

\section{REFERENCES}

Frankfurt, H. (1988). The importance of what we care about: Philosophical essays. Cambridge: Cambridge University Press.

Frankfurt, H. (1992). The faintest passion. Proceedings and Addresse of the American Philosophical Association, 66, 5-16. doi: $10.2307 / 3130658$ 